\title{
Mesangial Cells Cultured from Pregnant Rats Display Reduced Reactivity to Angiotensin II: the Role of Relaxin, Nitric Oxide and AT2 Receptor
}

\author{
Lucimeire N. Carvalho Priscila C. Cristovam Clévia S. Passos Mirian A. Boim \\ Department of Medicine - Renal Division, Federal University of São Paulo, São Paulo
}

\section{Key Words}

Pregnancy • Mesangial cells $•$ Intracellular calcium • Relaxin • AT2 receptor • Nitric oxide

\begin{abstract}
Background/Aims: Pregnancy is characterized by vasodilatation and increased glomerular filtration rate (GFR), despite overstimulation of the renin angiotensin system (RAS). The mesangial cells (MCs) influences GFR and when cultured from pregnant rats displays refractoriness to Ang II. We evaluated the role of relaxin (RLX) and its receptor (RXFP1), nitric oxide (NO) and the AT2 receptor in this response. Methods: MCs cultured from kidneys of virgin (V) and pregnant (P) Wistar rats were treated with RLX or AT2 receptor blocker PD123319 or NO synthase inhibitor L-NAME. After $24 \mathrm{hr}$, intracellular calcium concentration ([Ca]i) was recorded before and after the addition of Ang II. Results: MCs from V group expressed AT2, RLX and RXFP1, whose levels were increased in P cells. Ang II induced a $150 \%$ increase in [Ca] $i$ in the $V$ cells and $85 \%(p<0.05)$ in the $P$ cells. $V$ cells treated with RLX displayed a similar response to that observed in $\mathrm{P}$ cells, suggesting that RLX can modulate the reactivity of the MCs to Ang II. L-NAME and PD123319 did not interfere in this response. Conclusion: Results suggest that RLX is a mediator of the refractoriness of the MCs to Ang II during pregnancy.
\end{abstract}

Copyright $@ 2012$ S. Karger AG, Basel

\section{Introduction}

Normal pregnancy is characterized by intrarenal vasodilatation, increased renal plasma flow (RPF) and increased glomerular filtration rate (GFR) [1, 2]. Pregnancy-associated vasodilatation has been, in part, attributed to increased circulating vasodilators, such as prostaglandins (PGs) [3], nitric oxide (NO) [3-5], and relaxin, a hormone that has been implicated as an important regulator of renal function during pregnancy [6, 7]. Relaxin is 
primarily synthesized by the corpus luteum, and serum levels increase soon after conception in humans and near day 8 of gestation in rats [8]. It has been suggested that the vasodilator actions of relaxin involve activation of inducible nitric-oxide synthase, (iNOS) [9].

The mesangial cell tone influences the GFR through its contraction and relaxation properties [10]. In a previous study, it was demonstrated that mesangial cells (MCs) cultured from 14-day pregnant rats were less responsive to Ang II when compared with the MCs from virgin rats [11]. This observation is relevant because, plasma Ang II levels are increased during pregnancy [12], in spite of systemic and intrarenal vasodilatation; thus, the MCs, similar to smooth muscle cells, can adapt to pregnancy by maintaining a relatively relaxed tone even in the presence of high levels of Ang II.

In the present study, we evaluated the possible mediators of the attenuated response of mesangial cells derived from pregnant rats to Ang II. Specifically we examined relaxin and nitric oxide as well as the AT2 receptor because binding of Ang II to this receptor triggers antagonistic effects of the AT1 receptor, including vasodilation $[13,14]$.

\section{Materials and Methods}

\section{Animals}

The experimental protocol was approved by the Ethical Committee of the Federal University of São Paulo (no. 01008/08). Adult female Wistar rats $(200-250 \mathrm{~g}$ ) were obtained from the animal care facility of the Federal University of São Paulo. Animals had free access to standard rat chow and tap water and were maintained in a temperature-controlled room $\left(23^{\circ} \mathrm{C}\right)$ in a $12 \mathrm{~h}$ light/dark cycle. Female rats were pair-housed with an adult male Wistar rat for 2-3 days, and the presence of sperm in the vaginal smears (verified daily) was considered day 1 of pregnancy. Age-matched virgin and 12-14 days pregnant rats, were anesthetized, and the kidneys were removed for primary mesangial cell culture. This gestation period was chosen because it is characterized by a maximum increase in renal plasma flow. The groups of cells were denoted as $\mathrm{V}$ (from virgin rats) and $\mathrm{P}$ (from pregnant rats).

\section{Primary culture of mesangial cells (MCs)}

The primary MCs were cultured using standard techniques, following glomerular isolation by differential sieving [15]. Glomeruli were isolated from freshly removed kidneys from virgin and pregnant rats and then plated at a density of approximately 300 glomeruli/cm in DMEM supplemented with $20 \%$ fetal bovine serum, $50 \mathrm{U} / \mathrm{ml}$ penicillin, $2.6 \mathrm{~g}$ of HEPES acid, and $2 \mathrm{mM}$ glutamine (Sigma-Aldrich Co., St. Louis, MO, USA). Cells were used between the third and fifth subcultures. The cultures were periodically checked for purity by testing for the presence of $\alpha$-actin and for the absence of factor VIII and cytokeratin.

\section{Experimental Groups}

After the 3rd subculture, mesangial cells isolated from Virgin ( $n=5)$ and Pregnant rats $(n=5)$ were maintained in DMEM culture medium containing $1 \%$ of FBS for $24 \mathrm{hr}$ and under the following treatments: $\mathrm{V}$ and P Control cells with no treatment; V and P cells treated with the AT2 receptor antagonist PD123319 $\left(10^{-6} \mathrm{M}\right)$ for $24 \mathrm{hr}$; V and P treated with a NOS inhibitor L-NAME $\left(10^{-3} \mathrm{M}\right)$ for $24 \mathrm{hr}$; V and P treated with relaxin (100ng/ml) for $24 \mathrm{hr}$. After the respective $24 \mathrm{hr}$ treatment, cells were prepared for determination of [Ca]i as described below. Additional $\mathrm{V}$ and $\mathrm{P}$ groups with no treatment were acutely stimulated with relaxin $(100 \mathrm{ng} / \mathrm{ml})$. Acute experiments were performed as follows: after baseline [Ca]i determinations relaxin was added to the bath and then [Ca]i was measured. It was allowed [Ca]i to return to basal levels when Ang II was added and [Ca]i estimated again. Human relaxin (RLX) was purchased from Phoenix Pharmaceuticals, Inc. (CA, USA) and the dose of $100 \mathrm{ng} / \mathrm{ml}$ corresponds to maximum concentration in the blood of pregnant rats [16-18]. PD123319, L-NAME and Angiotensin II were from Sigma-Aldrich Chemical Co. (St. Louis, MO, USA) and the doses used as previously determined [19-22].

Intracellular calcium ([Ca]i) measurements

The reactivity of the MCs to Ang II was estimated by the increase in [Ca]i levels induced by addition of $10^{-7} \mathrm{M}$ Ang II. Measurement of [Ca]i was performed by the Fura 2-AM incorporation method as previously 
described [11]. After confluence, the MCs $\left(10^{6}\right.$ cells $\left./ \mathrm{ml}\right)$ were resuspended in $2.5 \mathrm{ml}$ of Tyrode buffer (137 $\mathrm{mM} \mathrm{NaCl}, 2.68 \mathrm{mM} \mathrm{KCl}, 1.36 \mathrm{mM} \mathrm{CaCl} 22 \mathrm{H}_{2} \mathrm{O}, 0.49 \mathrm{mM} \mathrm{MgCl}{ }_{2} 6 \mathrm{H}_{2} \mathrm{O}, 12 \mathrm{mM} \mathrm{NaHCO}_{3^{\prime}} 0.36 \mathrm{mM} \mathrm{NaH}_{2} \mathrm{PO}_{4}$, and $5.5 \mathrm{mM}$ D-glucose) containing $0.2 \%$ bovine serum albumin and left to stand in a $\mathrm{CO}_{2}$ incubator at $37^{\circ} \mathrm{C}$ for 30 minutes. The cell suspension was then centrifuged, and the pellet was resuspended in $2.5 \mathrm{ml}$ of albuminfree Tyrode and transferred to a quartz cuvette for autofluorescence determination in a spectrofluorimeter (Photon Technology International, Ontario, Canada). Measurements were made at excitation wavelengths of 340 and $380 \mathrm{~nm}$ with emission at $505 \mathrm{~nm}$. The autofluorescence ratio was less than $10 \%$. The MCs were then incubated with $0.01 \%$ Pluronic-127 detergent and $2 \mu \mathrm{M}$ of Fura 2-AM. Following this, the samples were read in the excitation range of 300 to $400 \mathrm{~nm}$, with emission at $520 \mathrm{~nm}$. In the esterified form, the maximum fluorescence of Fura 2-AM was observed at $390 \mathrm{~nm}$. Within three hours, the indicator was transformed to its acidic form, Fura-2, and the fluorescence peak shifted to $350 \mathrm{~nm}$, indicating that the maximum amount of indicator was incorporated into the cell suspension. The cells were washed with $15 \mathrm{~mL}$ of Tyrode and centrifuged at $1500 \mathrm{rpm}$ for four minutes. The supernatant was discarded, and the pellet was resuspended in $2.5 \mathrm{~mL}$ of Tyrode and transferred to a spectrofluorimeter programmed for excitation at two wavelengths ( 340 and $380 \mathrm{~nm}$ ) with emission at $505 \mathrm{~nm}$ with constant stirring at $37^{\circ} \mathrm{C}$. The first reading of this phase corresponded to the basal [Ca]i levels. The cells were then stimulated with Ang II $\left(10^{-7} \mathrm{M}\right)$. At the end of each experiment, $50 \mu \mathrm{M}$ digitonin, $1 \mathrm{mM} \mathrm{MnCl}{ }_{2}$ manganese chloride and $2 \mathrm{mmol} / \mathrm{L}$ ethylene gylcol tetraacetic acid were added to the cells. The results are reported as the ratio of the 340 and $380 \mathrm{~nm}$ wavelengths, relative to digitonin, which was set at $100 \%$. The [Ca]i was estimated by the formula of Grynkiewicz et al. [23].

\section{mRNA expression levels}

The mRNA expression levels of relaxin (RLX), its receptor (RXFP1) and the AT2 receptor were measured by quantitative real-time PCR. Total RNA was purified using the phenol and guanidine isothiocyanate-cesium chloride method (TRIzol kit; Life Technologies, Carlsbad, CA, USA). The RNA pellets were resuspended in RNase-free water. Two micrograms of total RNA were pretreated with DNase and then reverse transcribed into cDNA by the addition of a reaction mix, containing $0.5 \mathrm{mg} / \mathrm{mL}$ oligodT, $10 \mathrm{mM}$ dithiothreitol, $0.5 \mathrm{mM}$ dNTPs (Pharmacia Biotech, Pittsburgh, PA, USA), and $200 \mathrm{U}$ of reverse transcriptase (Superscript RT; Life Technologies, Carlsbad, CA, USA). The mixture was incubated at $37^{\circ} \mathrm{C}$ for $1 \mathrm{hr}$ and then at $95{ }^{\circ} \mathrm{C}$ for $5 \mathrm{~min}$. Primer sequences for the amplification of relaxin, RXFP1 and AT2 receptors were based on cDNA sequences obtained from GenBank and were designed using the Designer PCR software (Research Genetics, Huntsville, AL, USA). The following primer sequences were used (forward and reverse, respectively): RLX (tttcgatatgacgttgaaatgcc and aatccttccaagctaacaacgga), RXFP1 (tgggctcattggccgttctg and actccattcgtgccgtagtag), AT2 (cagtggtctgctgggattgc and ccatccaggtcagagcatcc) and $\beta$-actin (cctctatgccaacacagtgc and acatctgctggaaggtggac), which was used as an internal control. For each PCR set, negative controls (for contamination from exogenous sources) were included by replacing cDNA with water. Real-time RT-PCR was performed using the GeneAmp 5700 and ABI Prism 7700 Sequence Detection Systems (Applied Biosystems, Foster City, CA, USA). Real-time PCR product accumulation was monitored using the intercalating dye SYBR Green I (Molecular Probes, Carlsbad, CA, USA). Fluorescence for each cycle was quantitatively analyzed using the ABI Prism 7700 Sequence Detection System (Applied Biosystems). At the end of PCR amplification, the temperature was increased from $60^{\circ} \mathrm{C}$ to $95^{\circ} \mathrm{C}$ at a rate of $2^{\circ} \mathrm{C} / \mathrm{min}$. Fluorescence was measured every $15 \mathrm{sec}$ to construct the melting curve, which was used to verify the absence of nonspecific amplification products. The results were normalized to $\beta$-actin amplification, and the relative gene expression of each molecule, expressed in arbitrary units, was calculated by using the control group (V cells) as the standard.

\section{Western Blot Analysis}

The MCs were lysed in ice-cold purification buffer (50 mM Tris, pH 8.0; $150 \mathrm{mM} \mathrm{NaCl}$; $1 \%$ NP-40; $0.5 \%$ sodium deoxycholate; $0.1 \%$ sodium dodecyl sulfate (SDS); $2.5 \mathrm{mM}$ EDTA; $1 \mathrm{mM}$ phenylmethylsulfonyl fluoride; and $44 \mathrm{mM}$ o-phenanthroline). The samples were centrifuged, and the protein concentration was determined by the Folin method using reagents from Bio-Rad (Bio-Rad DC Protein Assay; Hercules, CA, USA). Fifty micrograms of protein were resolved on a $10 \%$ SDS polyacrylamide gel and transferred to a nitrocellulose membrane (Amersham Pharmacia Biotech, Piscataway, NJ, USA) at $4{ }^{\circ} \mathrm{C}$ using transfer buffer containing $25 \mathrm{mM}$ Tris-HCl, $192 \mathrm{mM}$ glycine, and 20\% methanol. Nonspecific binding was blocked with $5 \%$ nonfat dry milk in TBS buffer containing $10 \mathrm{mM}$ Tris-HCl (pH 7.5) and $200 \mathrm{mM} \mathrm{NaCl}$. The immunoblots 
Table 1. [Ca]i values in MCs from Virgin and Pregnant groups. $\mathrm{p}<0.05:{ }^{*}$ vs Basal: " vs Virgin. [Ca]i was measured under basal (unstimulated) conditions and after addition of $10^{-7} \mathrm{M}$ AngII.

\begin{tabular}{llc}
\hline $\begin{array}{l}{[\mathrm{Ca}] \mathrm{i}} \\
(\mathrm{nM})\end{array}$ & $\begin{array}{l}\text { Virgin } \\
(\mathrm{n}=5)\end{array}$ & $\begin{array}{c}\text { Pregnant } \\
(\mathrm{n}=5)\end{array}$ \\
\hline Basal & $124 \pm 16$ & $159 \pm 13$ \\
After Ang II & $313 \pm 19^{*}$ & $297 \pm 36^{*}$ \\
\% of increase & $161 \pm 12$ & $87 \pm 15^{\#}$ \\
\hline
\end{tabular}

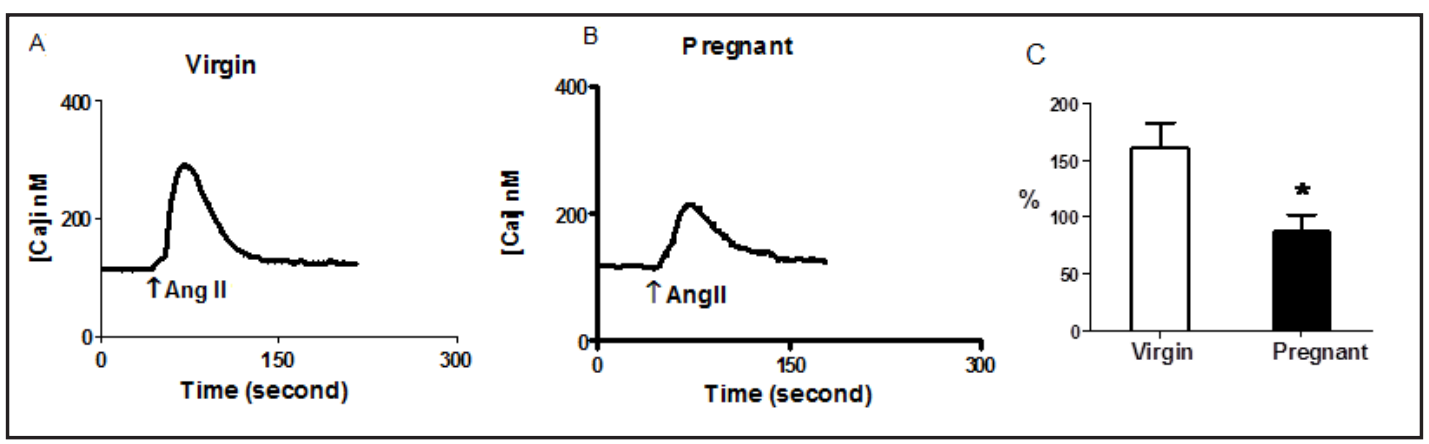

Fig. 1. Effect of Ang II on [Ca]i. Representative traces of [Ca]i in response to Ang II $\left(10^{-7} \mathrm{M}\right)$ : (A) Cells of the $\mathrm{V}$ group ( $n=5$ ); (B) Cells of the P group ( $n=5)$. (C) The peak [Ca]i, after stimulation with Ang II, was expressed as percentage of increase in $[\mathrm{Ca}] \mathrm{i},{ }^{*} \mathrm{p}<0.05$ : vs. control.

were then incubated overnight at $4^{\circ} \mathrm{C}$ with the primary polyclonal antibodies against the following: relaxin (Abcam Inc., Cambridge, UK), RXFP1 (Abcam Inc., Cambridge, UK), AT2 receptor (Santa Cruz Biotechnology Inc., Santa Cruz, CA, UK), and $\beta$-actin (Sigma-Aldrich Co., St. Louis, MO, USA). Subsequently, the membranes were washed 3 times with TBS buffer and then incubated for $1 \mathrm{hr}$ at $4^{\circ} \mathrm{C}$ with an anti-rabbit peroxidaseconjugated secondary antibody (Sigma-Aldrich Co., St. Louis, MO, USA). Detection of specific protein bands was performed with a Luminol detection system (Immobilon Western, Chemiluminescence HRP substrate; Millipore Corporation, Billerica, MA, USA). Then, each membrane was transferred to a photodocumentation system, the Luminescent Image Analyzer (LAS 4000 - Fuji, Tokyo, Japan). The Image Gauge software, version 3.1 (Fuji, Tokyo, Japan) was used for densitometric analysis of the bands. The results were normalized to $\beta$-actin expression, which was used as a positive endogenous control and expressed as a percentage of the control group ( $\mathrm{V}$ cells).

\section{Statistical Analysis}

The results are presented as the means \pm standard error. Differences in the basal [Ca]i concentrations between virgin and pregnant rats were evaluated using unpaired Student's t-test, whereas the [Ca]i variations in response to Ang II in the same group was analyzed by paired Student's t-test. One-way ANOVA analysis was used to determine the differences among groups. The level of statistical significance was defined as $\mathrm{p} \leq 0.05$.

\section{Results}

Under unstimulated (basal) conditions, the mean [Ca]i did not significantly differ between virgin and pregnant groups (Table 1), however, the increase in [Ca]i induced by Ang II was significantly lower in MCs in the pregnant group compared to those from the virgin group as it can be observed in the representative traces shown in Fig. 1. As a result the calculated percentage of increase in [Ca]i after Ang II stimulus, was significantly lower in P group compared to $\mathrm{V}$ cells (control), as depicted in panel C. The mRNA expression levels of relaxin, RXFP1 and AT2 receptors were significantly increased in the MCs from the pregnant group, compared with virgin group (Fig. 2). The protein expression levels, estimated by 
Fig. 2. mRNA expression levels. The results were obtained from RT-real time PCR reactions in triplicate. The values for the pregnant (P) group were calculated with the virgin $(\mathrm{V})$ group as the standard for each molecule. Bars represent the mean values for the $V(n=5)$ and $P(n=5)$ groups. ${ }^{*} p<0.05$ : vs. virgin.

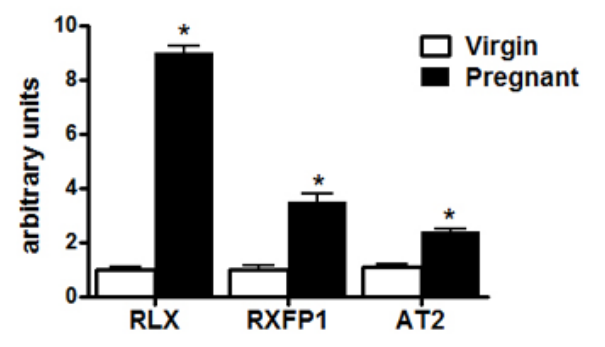

Fig. 3. Protein expression. A: Representative gel electrophoresis for relaxin (RLX), relaxin receptor (RXFP1) and the AT2 receptor ( $n=4$ for each group). B: Graphical representation of the bands quantified by densitometry and normalized for $\beta$-actin. The values were expressed as percentage changes compared to the virgin group, set at $100 \%$. ${ }^{*} \mathrm{p}<0.05$ : vs. virgin.
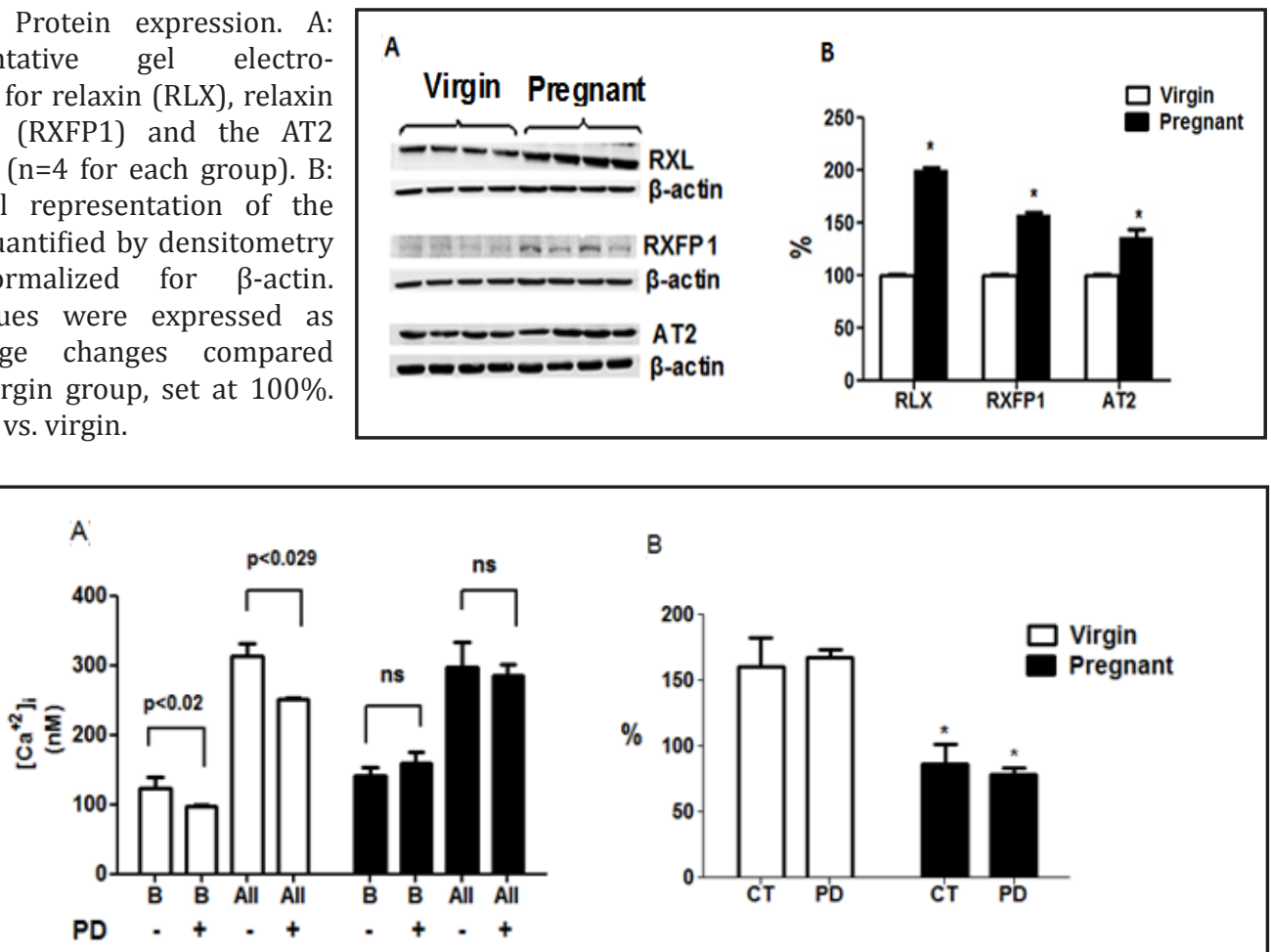

B

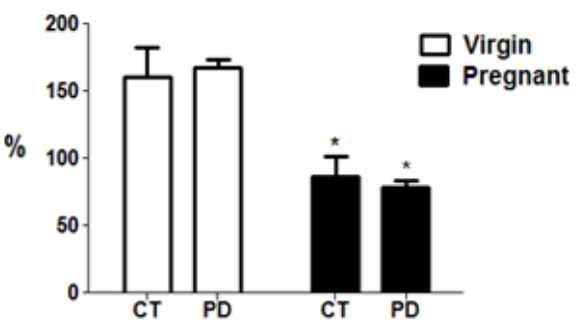

Fig. 4. Effect of PD123319 on [Ca]i. A: Absolute values of [Ca]i obtained before (B) and after Ang II (AII) addition to the MCs of the $V(n=5)$ and $P(n=5)$ groups, with and without PD123319 (PD) treatment. B: Percentage change in [Ca]i, after Ang II addition in V and P groups in the absence (CT) and presence of PD. $* \mathrm{p}<0.05$ vs. control.

western blot, coincided with the mRNA profile as shown in Figure 3. Representative blots probed with specific antibody for each molecule are shown in Fig. 3A and the quantification of bands is shown in Fig. 3B. The MCs, under control conditions (V), express both relaxin and its receptor, whereas the MCs cultured from pregnant rats showed significant increases in both. There was also a slightly but significant rise in the AT2 protein in P cells.

As shown in Fig. 4A, treatment of cells with the AT2 antagonist, PD123319 (PD), over $24 \mathrm{hr}$ induced a slight but significant decrease in baseline [Ca]i in the virgin group. Additionally, the Ang II-induced increase in [Ca]i was lower in PD-treated V cells compared with untreated V cells; however, the percentage change between the treated and untreated groups was not significant (Fig. 4B). In contrast, PD123319 did not affect either the baseline [Ca]i or the attenuated response of the P cells to Ang II .

Figure 5 shows the average values of [Ca]i in groups of cells treated with L-NAME for $24 \mathrm{hr}$; a significant decrease in the baseline [Ca]i in $\mathrm{V}$ cells was observed. The increase in 


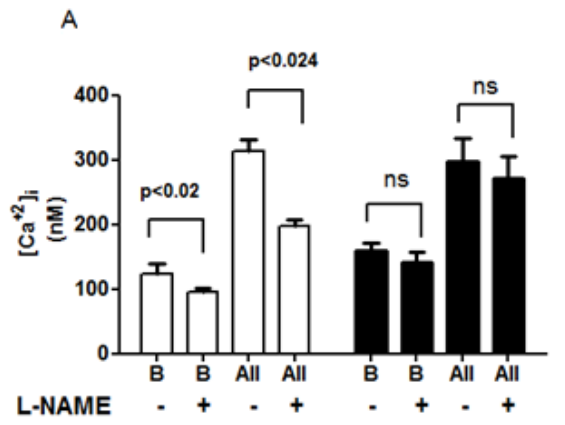

B
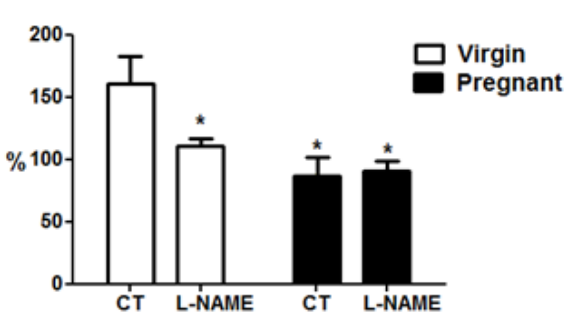

Fig. 5. Effect of L-NAME on [Ca]i. A: Absolute values of [Ca]i obtained before and after Ang II (AII) addition in MCs of the $V(n=5)$ and $P(n=5)$ groups with and without treatment with L-NAME. B: Percentage changes in [Ca]i, after Ang II addition to the V and P groups in the absence (CT) and presence of L-NAME. *p<0.05 vs. control (V).
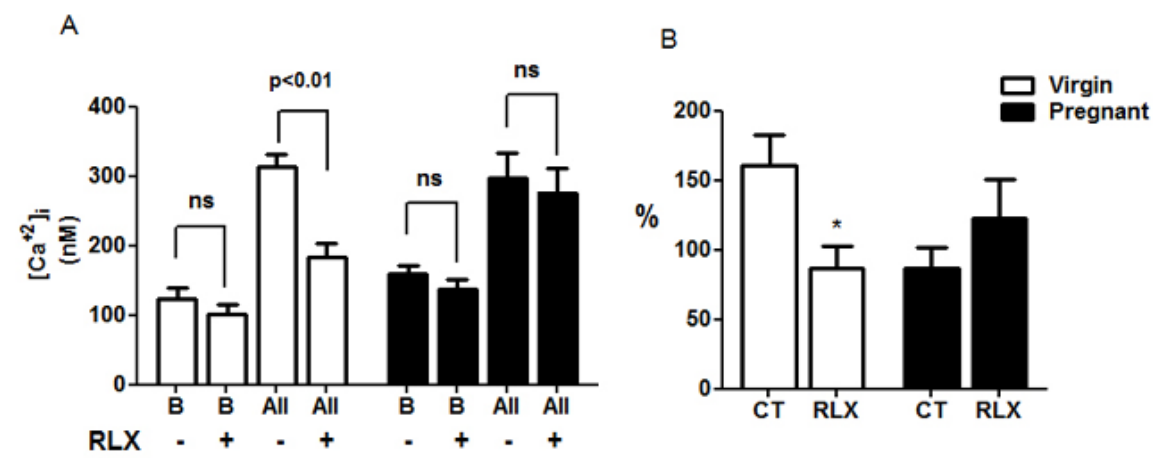

Fig. 6. Effect of relaxin on [Ca]i. A: Absolute values of [Ca]i obtained before (B) and after Ang II (AII) addition in MCs of the $V(n=5)$ and $P(n=5)$ groups with and without treatment with relaxin (RLX). B: Percentage changes in [Ca]i, after Ang II addition in the $\mathrm{V}$ and $\mathrm{P}$ groups in the absence (CT) and presence of relaxin. $* \mathrm{p}<0.05$ vs. control.

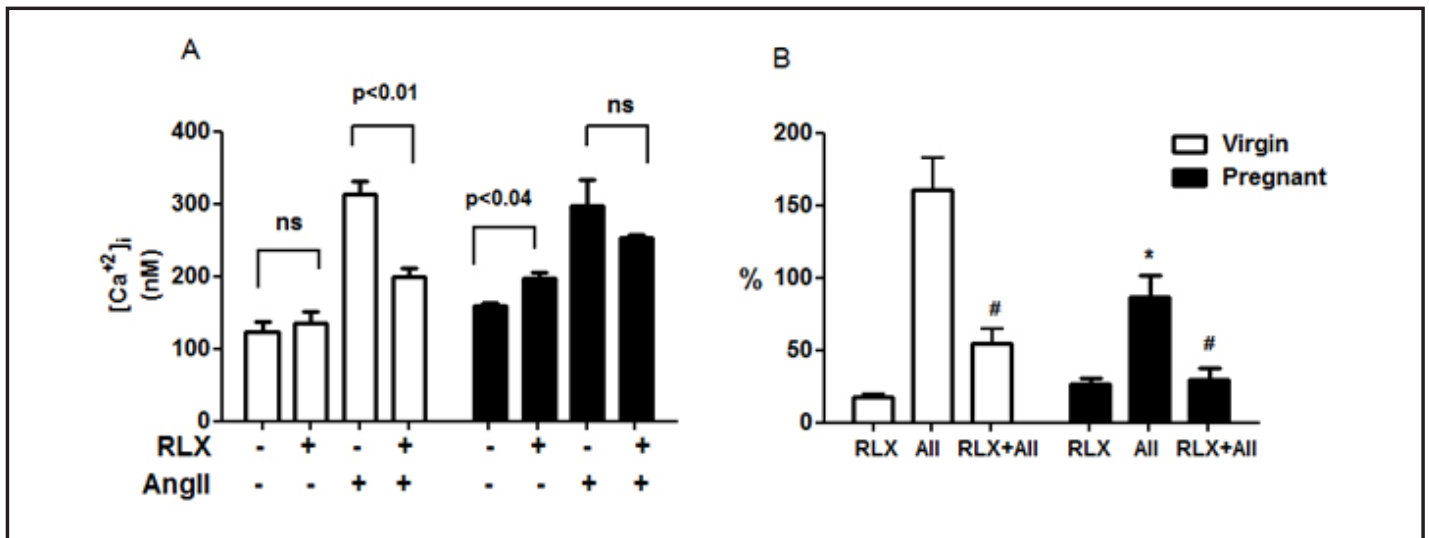

Fig. 7. Acute effects of relaxin. After baseline [Ca]i measurements, relaxin $(100 \mathrm{ng} / \mathrm{ml})$ was added to the cell suspension, followed by the addition of Ang II. A: absolute values; B: Percentage changes ( $n=5$ for each group), p< 0.05: *vs. V+Ang II; \#vs. Ang II.

[Ca]i was also diminished by L-NAME in V cells (Fig. 5A). This difference still persisted when [Ca]i was expressed as percentage of increase (Fig. 5B). Similar to the results observed with PD123319, L-NAME did not affect either the baseline [Ca]i or the response of the P cells to Ang II. 
Figure 6 shows the response of the MCs in both groups after stimulation for $24 \mathrm{hr}$ with relaxin. There was no change in the baseline [Ca] in either the V or P groups (Fig. 6A). Relaxin caused a lower response to Ang II in $V$ cells but had no effect on the response of P cells to Ang II. The same profile was observed when [Ca]i was expressed as a percentage change (Fig. 6B)

Acute addition of relaxin to the MCs produced a slight but significant increase in [Ca] $\mathrm{i}$ in the P group (Fig. 7A). However, the increase in [Ca]i produced by Ang II was significantly attenuated in the presence of relaxin in both $\mathrm{V}$ and $\mathrm{P}$ cells. This effect can be clearly seen in Fig. 7B, where the values are represented as the percentage changes.

\section{Discussion}

The present study aimed to evaluate some potential mediators of the hyporeactivity to Ang II of MCs cultured from pregnant rats [11]. In the present study, we confirmed that the MCs from pregnant rats are under responsive to Ang II treatment, and displayed a slight increase in [Ca]i when compared with the response of cells from virgin animals. This behavior was similar to that observed in vascular smooth muscle cells from pregnant rats [24], suggesting the presence of a contra-regulatory mechanism, which could maintain the cellular tone even in the presence of high levels of Ang II, typical of pregnancy. The results found here point to relaxin as a potential mediator of the refractoriness observed in the MCs of the P group, as also described in other cell types, including vascular smooth muscle cells and endothelial cells [21].

Interestingly, relaxin was constitutively expressed in the MCs cultured from V rats. It has been demonstrated that relaxin is present outside of the reproductive organs, such as in the kidney, where the function is mainly related to antifibrotic property $[25,26]$. This function could explain the presence of relaxin in the MCs cultured from non-pregnant rats and suggests that these cells may constitute a site of intrarenal production of relaxin. During pregnancy, the circulating levels of relaxin are increased, and the relaxin receptor RXFP1 is upregulated in many tissues including the kidney [11], but there is no available data on intrarenal production of relaxin during pregnancy. We found that the levels of relaxin were significantly upregulated in cells of the pregnant group, suggesting a potential role for relaxin in the MCs function during pregnancy, including the reduced reactivity of these cells to vasoconstrictor agents, such as Ang II. In addition, we observed that both acute and 24 $\mathrm{hr}$ administration of relaxin induced hyporeactive response to Ang II in the control V cells similar to that displayed by the P cells. This result supports our hypothesis that relaxin is a mediator of the attenuated response of the MCs cultured from pregnant rats to Ang II in vitro.

In contrast to relaxin, both the AT2 receptor antagonist (PD123319) and NOS inhibitor (L-NAME) did not significantly change the reduced response of the P cells to Ang II. The AT2 receptor was upregulated in P cells, and since it has been implicated in the gestational decline of systolic blood pressure (SBP), at least in mice [27], we expected to find that the AT2 receptor would have a role in the reduced reactivity of MCs to Ang II. The results, while unexpected, suggest that AT2 activation does not appear to be a relevant pathway in the refractoriness of the pregnant MCs to Ang II. Similarly, NOS inhibition with L-NAME did not modify the low reactivity of the P cells to Ang II. Interestingly, apart from the relaxation property of NO, it has been demonstrated that relaxin can act through activation of NO signaling $[20,28]$. Moreover, we have previously observed that MCs cultured from pregnant rats showed a significant increase in the mRNA expression of inducible NOS [11]. While our results are inconsistent with this previous study, there are at least 2 possible reasons for our observations: 1) NO is not involved in the hyporeactivity of P cells; and 2) L-NAME was not effective in inhibiting iNOS in P cells, which is intriguing since L-NAME was effective to reduce the response to Ang II in MCs from V rats. Thus, further studies are needed to clarify this issue.

In summary, the results of this study support a different paradigm regarding the MCs from virgin and pregnant rats, and this in vitro model may be useful in evaluating the effects 
of certain stimuli induced in vivo. Our results suggest that relaxin is a potential mediator of the refractoriness of the MCs to Ang II and may modulate the mesangial cell tone during Ang II stimulation, thereby contributing to keep a higher GFR even under the high activity of RAS typical of pregnancy.

\section{Acknowledgements}

This work was supported by grants from Fundação de Amparo a Pesquisa do Estado de São Paulo (FAPESP), Conselho Nacional de Desenvolvimento Científico e Tecnológico (CNPq), Coordenação de Aperfeiçoamento de Pessoal de Nível Superior (CAPES) and Fundação Oswaldo Ramos (FOR).

\section{References}

1 Baylis C: The determinants of renal hemodynamics in pregnancy. Am J Kidney Dis 1987;9:260-264.

2 Conrad KP: Mechanisms of renal vasodilation and hyperfiltration during pregnancy. J Soc Gynecol Investig 2004;11:438-448.

3 Bobadilla RA, Anguiano L, Perez-Alvarez V, Lopez Sanchez P: Pregnancy influence on the vascular interactions between nitric oxide and other endothelium-derived mediators in rat kidney. Can J Physiol Pharmacol 2003;81:1-8.

4 Baylis C, Qiu C: Importance of nitric oxide in the control of renal hemodynamics. Kidney Int 1996;49:17271731.

-5 Danielson LA, Conrad KP: Acute blockade of nitric oxide synthase inhibits renal vasodilation and hyperfiltration during pregnancy in chronically instrumented conscious rats. J Clin Invest 1995;96:482490.

6 Novak J, Danielson LA, Kerchner LJ, Sherwood OD, Ramirez RJ, Moalli PA, Conrad KP: Relaxin is essential for renal vasodilation during pregnancy in conscious rats. J Clin Invest 2001;107:1469-1475.

7 Debrah DO, Novak J, Matthews JE, Ramirez RJ, Shroff SG, Conrad KP: Relaxin is essential for systemic vasodilation and increased global arterial compliance during early pregnancy in conscious rats. Endocrinology 2006;147:5126-5131.

8 Sherwood 0: Relaxin; in Knobil E, Neill JD (eds.): The Physiology of Reproduction. Raven Press, New York, USA, 1994.

9 Nistri S, Bani D: Relaxin receptors and nitric oxide synthases: Search for the missing link. Reprod Biol Endocrinol 2003;1:5.

10 Baylis C: The mechanism of the increase in glomerular filtration rate in the twelve-day pregnant rat. J Physiol 1980;305:405-414.

11 Ferreira VM, Gomes TS, Reis LA, Ferreira AT, Razvickas CV, Schor N, Boim MA: Receptor-induced dilatation in the systemic and intrarenal adaptation to pregnancy in rats. PLoS One 2009;4:e4845.

$\checkmark 12$ Wilson M, Morganti AA, Zervoudakis I, Letcher RL, Romney BM, Von Oeyon P, Papera S, Sealey JE, Laragh JH: Blood pressure, the renin-aldosterone system and sex steroids throughout normal pregnancy. Am J Med 1980;68:97-104.

13 Hein L, Barsh GS, Pratt RE, Dzau VJ, Kobilka BK: Behavioural and cardiovascular effects of disrupting the angiotensin ii type-2 receptor in mice. Nature 1995;377:744-747.

14 Carey RM: Update on the role of the at2 receptor. Curr Opin Nephrol Hypertens 2005;14:67-71.

15 Greenspon SA, Krakower CA: Direct evidence for the antigenicity of the glomeruli in the production of nephrotoxic serums. AMA Arch Pathol 1950;49:291-297.

16 Bathgate RA, Ivell R, Sanborn BM, Sherwood OD, Summers RJ: International union of pharmacology lvii: Recommendations for the nomenclature of receptors for relaxin family peptides. Pharmacol Rev 2006;58:7-31. 


\section{Cellular Physiology $\quad$ Cell Physiol Biochem 2012;30:1456-1464 and Biochemistry \\ www.karger.com/cpb}

17 Heng K, Ivell R, Wagaarachchi P, Anand-Ivell R: Relaxin signalling in primary cultures of human myometrial cells. Mol Hum Reprod 2008;14:603-611.

18 Cardoso LC, Nascimento AR, Royer C, Porto CS, Lazari MF: Locally produced relaxin may affect testis and vas deferens function in rats. Reproduction 2010;139:185-196.

-19 Wong PC, Price WA, Chiu AT, Duncia JV, Carini DJ, Wexler RR, Johnson AL, Timmermans PB: Nonpeptide angiotensin ii receptor antagonists. Viii. Characterization of functional antagonism displayed by dup 753, an orally active antihypertensive agent. J Pharmacol Exp Ther 1990;252:719-725.

20 McGuane JT, Debrah JE, Sautina L, Jarajapu YP, Novak J, Rubin JP, Grant MB, Segal M, Conrad KP: Relaxin induces rapid dilation of rodent small renal and human subcutaneous arteries via pi3 kinase and nitric oxide. Endocrinology 2011;152:2786-2796.

-21 Failli P, Nistri S, Mazzetti L, Chiappini L, Bani D: Effects of relaxin on vascular smooth muscle and endothelial cells in normotensive and hypertensive rats. Ann N Y Acad Sci 2005;1041:311-313.

-22 Hadad SJ, Ferreira AT, Oshiro ME, Neri R, Schor N: Alteration of cytosolic calcium induced by angiotensin ii and norepinephrine in mesangial cells from diabetic rats. Kidney Int 1997;51:87-93.

23 Grynkiewicz G, Poenie M, Tsien RY: A new generation of ca2+ indicators with greatly improved fluorescence properties. J Biol Chem 1985;260:3440-3450.

24 Murphy JG, Khalil RA: Gender-specific reduction in contractility and [ca(2+)](i) in vascular smooth muscle cells of female rat. Am J Physiol Cell Physiol 2000;278:C834-844.

25 Samuel CS, Hewitson TD: Relaxin in cardiovascular and renal disease. Kidney Int 2006;69:1498-1502.

26 Samuel CS, Zhao C, Bond CP, Hewitson TD, Amento EP, Summers RJ: Relaxin-1-deficient mice develop an age-related progression of renal fibrosis. Kidney Int 2004;65:2054-2064.

27 Carey LC, Rose JC: The midgestational maternal blood pressure decline is absent in mice lacking expression of the angiotensin ii at2 receptor. J Renin Angiotensin Aldosterone Syst 2011;12:29-35.

-28 Conrad KP: Unveiling the vasodilatory actions and mechanisms of relaxin. Hypertension 2010;56:2-9. 